RECURSOS HUMANOS 


\title{
EMPODERAMENTO DE DELEGADAS: O QUE OS HOMENS PENSAM SOBRE ISSO?
}

\author{
EMPOWERMENT OF DELEGATES: WHAT MEN THINK ABOUT IT?
}

Rosilaine Aparecida Pinto

Centro Universitário Novos Horizontes

Marlene Catarina de Oliveira Lopes Melo Centro Universitário Novos Horizontes
Data de submissão: 07 dez. 20 | 6. Data de aprovação:

20 fev. 2017. Sistema de avaliação: Double blind review.

Universidade FUMEC / FACE. Prof. Dr. Henrique Cordeiro

Martins. Prof. Dr. Cid Gonçalves Filho.

RESUMO

Esta pesquisa analisou a percepção dos delegados da Polícia Civil de Ribeirão das Neves acerca do empoderamento profissional das delegadas do mesmo município. Caracteriza-se como uma pesquisa descritiva, qualitativa, um estudo de caso com os delegados das delegacias de Polícia Civil de Ribeirão das Neves, região metropolitana de Belo Horizonte/MG. Os resultados apontaram o desenvolvimento do processo de empoderamento das delegadas, com destaque para o reconhecimento dos delegados da qualificação e contribuição profissional da delegada para a instituição e para a sociedade. Identificou-se que os valores tradicionais da cultura machista e patriarcal ainda reproduzem estereótipos e barreiras de gênero na instituição policial, mas a maior presença das delegadas tem contribuído para o enfraquecimento dessa cultura e favorecido o processo de empoderamento da mulher.

PALAVRAS-CHAVE

Gênero. Empoderamento. Delegadas. Dominação Masculina. Polícia Civil. 


\begin{abstract}
This research analises the perception of delegates Civil Police in Ribeirão das Neves about the professional empowerment of delegates women in the same municipality. It is characterized as a descriptive research, qualitative, a case study with delegates from Police Civil station in Ribeirão das Neves, Belo Horizonte metropolitan region-MG. The results have highlighted the development of delegate empowerment process, with emphasys for recognition of delegates for professional - qualification and professional contribuition towards instituition and society. It was identified the tradition values machista culture and parent culture that are still responsible for stereotype reproduction an barrier of the gender in the police instituition.
\end{abstract}

\title{
KEYWORDS
}

Gender relation. Empowerment. Delegates. Male Domination. Civil Police.

\section{INTRODUÇÃO}

As discussões acerca das relações de gênero emergiram da efervescência do movimento feminista das décadas de 1960 e 1970 nos Estados Unidos. Tinham por finalidade romper com os princípios da dominação masculina, que justificavam que as distinções quanto à condição e posição do homem e da mulher na sociedade eram fruto das diferenças sexuais existentes entre eles, apresentando a ordenação social como algo natural e indiscutível (SCOTT, 1991). Os princípios da dominação masculina legitimam a condição do homem como sexo dominante, privilegiando-o na ocupação de posições de poder nas esferas social, política e econômica, dificultando o acesso das mulheres a esses ambientes e posições, considerados apropriados a eles (BOURDIEU, 20I0).

Apesar dos princípios de dominação masculina influenciarem na ordenação social, uma estratégia utilizada para elimi- ná-los e (re)significar o papel da mulher na sociedade é o empoderamento (PROGRAMA DAS NAÇÕES UNIDAS PARA O DESENVOLVIMENTO - PNUD, 20I4), capaz de romper com essa condição vulnerável da mulher dominada, tradicionalmente construída por meio de valores, crenças e práticas sociais (COSTA, 2004; LISBOA, 2008; MELO; LOPES, 201 I ; MELO, 2012; PNUD, 20I4), além de contribuir para o desenvolvimento de um país, dada a representatividade numérica das mulheres e a contribuição social, política e econômica que podem dar ao se empoderarem (PNUD, 20l4).

Empoderamento pode ser entendido como a conquista da liberdade da mulher para fazer as suas próprias escolhas de vida (DEERE; LEÓN, 2002; COSTA, 2004; MALHOTA; SCHULER, 2005; MAHADEVI, 20I3; PORTER, 20I3; KABEER, 20I3) e, também, a capacidade de influenciar a vida de outras pessoas e o ambiente em 
que está inserida (DEERE; LEÓN, 2002; COSTA, 2004; SPREITZER, 2008; KLEBA; WENDAUSEN, 2009; KABEER, 20I3). empoderamento da mulher contribui para a mudança em sua vida desde a esfera doméstica até a organizacional.

Em se tratando de empoderamento no ambiente organizacional, de uma maneira geral, Melo (20I2) considera que esse acontece quando a mulher se capacita e qualifica, se sente segura, confiante e determinada quanto a suas escolhas e decisões, exerce influência nas relações de poder que participa, conquista a independência financeira, é reconhecida profissionalmente e contribui para o enfraquecimento da cultura patriarcalista da sociedade por meio do seu trabalho. Para a autora, este empoderamento organizacional pode ser analisado considerando seis fatores, que refletem as questões citadas: cognitivo analítico, subjetivo, político, econômico, social e cultural.

Observa-se que muitas mulheres optam pela carreira pública para alcançarem um posicionamento profissional valorizado, conquistando cargos e adentrando em áreas predominantemente ocupadas por homens (SADEK, 2009) desenvolvendo assim uma estratégia que contribui para seu empoderamento organizacional. Uma dessas áreas em que se tem notado a expansão da atuação profissional da mulher é a Polícia Civil. Em Minas Gerais nas duas últimas décadas o número de delegadas cresceu $150 \%$ e atualmente elas representam $28 \%$ da classe (SINDIPOMINAS, 20I4) e elas têm conquistado espaços importantes, um exemplo disso foi à nomeação em $2015 \mathrm{da}$ primeira Chefe de Polícia Civil em Minas Gerais (MINAS GERAIS, 20I5).

Entretanto, apesar desse crescimento, pode-se ainda perceber que o estereóti- po de delegado é atrelado a características masculinas, tidas como naturais do homem, como força física, capacidade de comando, imponência e coragem (HAGEN, 2006; BEZERRA; LOPES, 2008; SADEK, 2009; LOPES; MOTA BRASIL, 20I0; LOCATELLI et al., 20I3). Portanto, o fato da mulher ocupar a mesma posição que um homem pode não garantir $\mathrm{a}$ isonomia de gênero na instituição.

Salienta-se que em se tratando de empoderamento organizacional das mulheres, os homens não podem ser desconsiderados, pois as relações entre os gêneros no ambiente de trabalho influenciam diretamente nesse processo. $\mathrm{E}$ é baseado nisso que o objetivo desse trabalho é analisar a percepção dos delegados da Polícia Civil de Ribeirão das Neves acerca do empoderamento profissional das delegadas do mesmo município, com base no Modelo de Análise do Processo de Empoderamento, proposto por Melo (20I2).

\section{REFERENCIALTEÓRICO Relações de Gênero e Dominação Masculina}

Para as feministas das décadas de 1960 e 1970, "gênero" representava uma rejeição à justificativa de que as distinções sociais entre homens e mulheres eram determinadas pelo sexo e também uma rejeição à dominação masculina presente nas relações sociais (SCOTT, 199I; BOURDIEU, 20I0; LOURO, 20 I I). Scott (I99I) explica que "gênero" diz respeito às perspectivas dicotômicas dos papéis dos homens e das mulheres elaborados e reproduzidos nos contextos sociais históricos, que se apresentam como natural na evolução da sociedade. Melo (20II) acrescenta que "gênero" trata de uma identidade que está em cons- 
tante mudança, sofrendo reestruturações conforme "complexidades das relações sociais, políticas, econômicas, psicológicas, afetivas e culturais entre homens e mulheres, intermediadas pela estrutura social institucionalizada e não-institucionalizada da sociedade"(MELO, 20I I, p. 6).

As relações de gênero dizem respeito às ideias construídas pela sociedade sobre o que é ser homem e o que é ser mulher, bem como o que é masculino e feminino, bem como o que se espera entre homens e mulheres, entre os homens entre si e entre as mulheres entre si (PINTO; NUNES; FAZENDA, 20I4). Os debates sobre "gênero" devem confrontar os discursos sociais fixos que justificam as desigualdades entre homens e mulheres (SCOTT, I99I), desconstruindo e mostrando o caminho pelo qual ele foi construído e fundamentado como verdadeiro (SCOTT, I991; LAGARDE, 1996; LISBOA, 2002; BOURDIEU, 20I0). Louro (20II) enfatiza que ao admitir que não existe uma fórmula fixa do que é ser homem e mulher, é possível romper com os princípios de dominação masculina.

$\mathrm{Na}$ abordagem de Bourdieu (20l0), a origem da dominação masculina está nas significações sociais construídas acerca dos corpos, principalmente dos órgãos sexuais do homem e da mulher (BOURDIEU, 2010). Nessa perspectiva, a dominação masculina é justificada pela crença de que o homem possui uma posição de dominação em relação à mulher no ato sexual que se transfere naturalmente para á dominação na esfera social (BOURDIEU, 20I0), trazendo implicações em todas as esferas de atuação deles, pois pode ser identificado na sociedade uma distribuição desigual de poder, autoridade e prestígio, baseado no sexo (PINTO; NUNES; FAZENDA, 20I4).
No ambiente de trabalho refletem no desenvolvimento de atividades e nos campos de atuação, verificando-se a divisão sexual do trabalho, sendo as áreas tipicamente ocupadas por homens mais valorizadas que as por mulheres (HIRATA; KERGOAT, 2007;BRUSCHINI,2007;BOURDIEU,20I0; PINTO; NUNES; FAZENDA, 20I4). Dessa maneira, os homens podem ser privilegiados na ocupação de posições de poder e representação política, e ficando a atuação da mulher no espaço público limitada, sendo reservadas a elas atividades de submissão e de menor valor social (BOURDIEU, 2010 ; BRUSCHINI, 2007; PINTO; NUNES; FAZENDA, 20I4). Porém, as mulheres não estão fadadas a subjugação e, para romper com esses princípios culturais patriarcalistas o empoderamento feminino tem sido apontado como estratégia (COSTA, 2004; LISBOA, 2008; MELO, 20I2; PNUD, 20I4).

\section{Empoderamento da mulher no ambiente organizacional}

$\mathrm{Na}$ conceituação das feministas das décadas de 1960 e 1970 o empoderamento da mulher significava a alteração radical das estruturas e processos responsáveis por disseminar e reproduzir princípios de dominação masculina que reafirmavam a subordinação das mulheres nas relações de gênero (COSTA, 2004). De maneira geral, o empoderamento pode ser entendido como a conquista pelo indivíduo da liberdade de fazer suas próprias escolhas de vida em um ambiente em que não oferecia essa opção (KABEER, 200 I; DEERE; LEÓN, 2002; MAHADEVI, 20I3). Também, relaciona-se a conquista do poder de influenciar outros indivíduos, sendo seu posicionamento considerado nas resoluções dos problemas e nos processos de 
planejamento das decisões relativas ao grupo (DEERE; LEÓN, 2002, PANDEY, 20I3), sendo seu objetivo romper com os princípios históricos, sociais e culturais de uma sociedade sustentada pela ideologia patriarcal (COSTA, 2004; LISBOA, 2008; MELO, 20I2; RATHO, 20I3). Entretanto, não se trata de uma tarefa fácil, já que a dominação masculina é tratada como de ordem natural na humanidade (BOURDIEU, 20 I0; RATHO, 20I3).

Melo (2012) ressalta que o empoderamento da mulher, no contexto das relações de gênero implica a conquista de autonomia, que lhe dá poderes para controlar as decisões sobre a sua sexualidade, e sua participação no ambiente familiar, social e organizacional. No contexto organizacional, a autora propõe um modelo para análise do empoderamento, constituído por seis fatores: cognitivo analítico, subjetivo, político, econômico, fator social e cultural.

O objetivo do fator cognitivo analítico é analisar a importância da capacitação, do conhecimento e da qualificação continuada para o exercício da profissão e para o crescimento profissional (MELO, 20I2). O investimento em educação tem sido apontado como uma das estratégias utilizadas pelas mulheres para alcançarem o empoderamento (FEM, 2005; BRUSCHINI, 2007; SADEK, 2009; BOURDIEU, 20I0), pois além de criar melhores oportunidades de emprego (KABEER, 20I3), colabora para a entrada delas em ambientes profissionais mais valorizados.

fator subjetivo pretende identificar o desenvolvimento do empoderamento psicológico da mulher, por meio do desenvolvimento da autoestima, autoconfiança em sua competência profissional, autodeterminação e segurança na tomada de decisões
(MELO, 20I2). O empoderamento psicológico desenvolve o sentimento de capacidade habilitando-a com o controle sobre os seus atos e suas relações pessoais e sociais (SPREITZER, 2008; KLEBA;WENDAUSEN, 2009; MELO, 20 I 2).

No fator político é analisada a capacidade da mulher de se relacionar e buscar estratégias para conquistar espaços nas relações de poder, possibilitando maior autonomia e autoridade no ambiente organizacional e o acesso a alta hierarquia. Procura identificar as barreiras de gênero existentes nesse ambiente e o reconhecimento dessas barreiras por elas (MELO, 2012). Refere-se também, á influência política para organizar e alterar o ambiente em que está inserida, por meio de suas escolhas e decisões (FRIEDMANN, 1996; STROMQUIST, 1997; COSTA, 2004; MELO, 20 I 2).

O fator econômico propõe identificar a conquista da independência financeira e seu reflexo na vida profissional e pessoal da mulher (MELO, 20I2), sendo fundamental para o processo de empoderamento (MELO, 20 I 2; KABEER, 20 I3, PNUD, 20 I4, THE WORD BANK, 20 I4; EY, 20I4), pois a existência de estereótipos e preconceitos de gênero é bem maior em relação a muIheres que estão sob dependência financeira de outras pessoas (EY, 20I4).

$O$ fator social analisa se a mulher, por meio do seu trabalho, conquistou o reconhecimento organizacional, social e familiar e como esse reconhecimento afeta o seu desenvolvimento profissional (MELO, 20I2). Por fim, o fator cultural analisa se a cultura tem dificultado ou favorecido a participação das mulheres no mercado de trabalho. Verifica as alterações culturais produzidas pela inserção da mulher no mercado de trabalho e a contribuição do 
movimento dela para o enfraquecimento do patriarcalismo na sociedade. Todos os fatores do modelo estão relacionados em um construto dinâmico e complexo, sendo vivenciados de maneira múltipla e individualizada pelas mulheres.

\section{Trabalho Policial e as influências de Gênero}

Uma das áreas públicas em que se observa $\circ$ crescimento da participação das mulheres é na Polícia Civil, instituição construída em princípios e normas que carregam a simbologia dos princípios da dominação masculina (BEZERRA; LOPES, 2008; LOPES; MOTA BRASIL, 20 I0; LOCATELLI et al., 2013). Até 1970, somente delegados ocupavam os cargos de direção dessas instituições. A entrada das mulheres nessa área está relacionada às discussões incitadas pelos movimentos feministas acerca das relações de gênero na sociedade. Nesse período a instituição foi pressionada a agregar valores que fossem condizentes com as necessidades sociais emergentes e permitiu a entrada das mulheres (SOARES; MUSUMECI, 2005).

Todavia, apesar da entrada e crescimento das mulheres nessa instituição, de acordo com Hagen (2006), Bezerra e Lopes (2008), Sadek (2009) e Lopes; Mota Brasil (20I0), dentro da polícia as relações de gênero são influenciadas pelos princípios de dominação masculina. Pode-se identificar no trabalho policial uma classificação dos "trabalhos de homem" e dos "trabalhos de mulher": sendo aqueles atribuídos aos homens mais valorizados (SOARES; MUSUMECI, 2005; BEZERRA; LOPES, 2008). Ou seja, observa-se a divisão sexual do trabaIho, que pode refletir em maiores dificuldades à ascensão profissional da mulher.
O homem tradicionalmente é associado à força, virilidade, racionalidade, poder e comando, características que compõe o papel de dominador e o enquadram nas características tradicionais esperadas para o cargo policial (SADEK, 2009; BEZERRA e LOPES, 2008). Já a mulher associada à fragilidade, submissão, fraqueza, emoção e cuidados, compõe o papel de dominada, podendo encontrar, além das próprias dificuldades do cargo, o preconceito de ocupar um cargo que supostamente não condiz com seus atributos naturais (SADEK, 2009).

Hagen (2006) aponta que existem construções sociais que se tornaram senso comum acerca do trabalho policial que dificulta a atuação da mulher nessa área. Uma delas é que a atividade policial é uma atividade perigosa, que exige bom condicionamento físico, que pode levar à situações violentas e a locais socialmente desvalorizados.Todas essas características funcionais são associadas ao estereótipo do homem. Além disso, há uma disputa quanto ao que seria o "verdadeiro" trabalho policial. Um grupo de policiais homens acredita que 0 "verdadeiro" trabalho policial é aquele realizado nas atividades operacionais da rua. O outro grupo de policiais, homens e muIheres, que têm mais aptidão para as atividades realizadas dentro das delegacias, defende que nada adianta capturar o suspeito se não for capaz de reunir provas contra ele (HAGEN, 2006).

Ainda existe preconceito relacionado à simbologia das delegacias e de seus representantes (BEZERRA; LOPES, 2008; SILVEIRA, 20II). Existem as delegacias consideradas de cunho assistencialistas tipificadas "cadeiras cativas das delegadas", como a Delegacia de Defesa da Mulher, a Delegacia da Criança e do Adolescente. $E$ as de- 
legacias consideradas mais operacionais tipificadas "cadeiras cativas dos delegados", como a Divisão de Investigação Criminal, a Divisão de Antissequestro (BEZERRA; LOPES, 2008), constituindo-se, assim, os setores específicos para delegados(as).

Por outra ótica, salienta-se que o homem nessa área também fica à mercê de preconceitos e estigmas (BEZZERRA; LOPES; 2008), pois carrega o "fardo" de ter que atender às expectativas sociais no que se refere ao seu posicionamento como homem (PINTO; NUNES; FAZENDA, 20I4), principalmente dentro dessas instituições de Polícia Civil, onde as exigências e expectativas são fundamentadas na legalidade dos princípios da dominação masculina no "exercício de comando, uso da força e da repressão" (BEZZERRA; LOPES; 2008, p.59).

\section{METODOLOGIA}

Esta pesquisa caracteriza-se como descritiva, de abordagem qualitativa. Como método de pesquisa utilizou-se o estudo de caso, pois se tratou de uma investigação detalhada de uma organização com o intuito de analisar os fatores envolvidos no fenômeno estudado (HARTLEY, 1999). $O$ estudo foi realizado nas delegacias da Polícia Civil de Ribeirão das Neves, na região metropolitana de Belo Horizonte. A unidade de análise foi constituída pelo trabalho das delegadas da Polícia Civil de Ribeirão das Neves.

Os sujeitos da pesquisa foram cinco delegados, dos seis delegados atuantes no município. Um delegado plantonista não se dispôs a participar desta pesquisa. Para a coleta dos dados, utilizou-se a entrevista semiestruturada (GODOY, 2006), adaptada para analisar o possível processo de em- poderamento das delegadas, na percepção dos delegados. As entrevistas foram realizadas nas delegacias de atuação de cada delegado, gravadas em áudio e transcritas, sendo codificadas de El a E5, preservando a identidade dos entrevistados e suas respectivas delegacias.

Para a análise dos dados recorreu-se a análise de conteúdo (BARDIN, I994). Essa análise não se atém somente às partes das entrevistas, mas ao conteúdo geral, possibilitando, assim, verificar e analisar as contradições da fala dos entrevistados. As categorias que orientaram a análise de conteúdo foram estabelecidas segundo os fatores do modelo de Análise do Processo de Empoderamento (MELO, 20I2): cognitivo analítico, subjetivo, político, social, fator econômico e cultural. Logo após procedeu-se a análise dos dados.

\section{Apresentação e Análise dos Resultados \\ Ambiência e caracterização dos sujeitos da pesquisa}

Ribeirão das Neves é um município mineiro localizado na região metropolitana de Belo Horizonte, com área de |55,54| $\mathrm{km}^{2}$, e população aproximada de 319.310 habitantes. $O$ crescimento da população de Ribeirão das Neves é influenciado pela existência de um complexo penitenciário de cinco unidades prisionais, que impacta no aumento do índice de criminalidade do município (SECRETARIA DE DEFESA SOCIAL, 20I5).

Existem sete delegacias da Polícia Civil em Ribeirão das Neves: Delegacia de Polícia Civil de Plantão; I ${ }^{a}$ Delegacia de Polícia Civil; Delegacia de Polícia Civil Especializada de Atendimento à Mulher; $2^{\mathrm{a}}$ Delegacia de Polícia Civil; $3^{a}$ Delegacia de Polícia 
Civil; Delegacia Regional de Polícia Civil e Delegacia Especializada de Homicídios. Destas, seis funcionam de segunda a sexta, de 8 horas às $18 \mathrm{~h}$ (regime de expediente) e uma (delegacia de plantão) funciona diariamente, 24 horas, sendo que cada delegado plantonista trabalha 24 horas e descansa 96 horas.Em regime de expediente são 4 delegadas e 2 delegados. A delegacia de plantão possui 5 delegados, 4 homens e I mulher.

As delegadas estão na direção das delegacias: I ${ }^{a}$ Delegacia de Plantão de Ribeirão das Neves; I ${ }^{a}$ Delegacia de Polícia Civil de Ribeirão das Neves; $2^{a}$ delegacia de Polícia Civil de Ribeirão das Neves; Delegacia Especializada de Atendimento a Mulher e Delegacia Regional de Ribeirão das Neves.

Foram ouvidos 5 delegados das delegacias: $10^{a}$ Delegacia Especializada de Homicídios de Ribeirão das Neves; $3^{a}$ delegacia de Polícia Civil de Ribeirão das Neves e 3 atuam na Delegacia de Plantão de Ribeirão das Neves. Em relação à faixa etária, 3 entrevistados têm idade entre 30 a 35 anos, I entre 36 e 40 anos e I entre 4 I e 44 anos. Quanto à naturalidade, 3nasceram em Belo Horizonte/Minas Gerais e 2 nasceram em cidades do interior de Minas Gerais. Todos são casados e 4 possui filhos. Todos possuem 2 anos de atuação no cargo.

\section{A Visão dos Delegados do Empoderamento das Delegadas Fator cognitivo analítico}

O conhecimento das delegadas é avaliado pelos delegados em três frentes: conhecimento teórico, técnico e prático. Em relação ao conhecimento teórico, eles percebem positivamente a contribuição das delegadas decorrente de sua qualificação profissional obtida pela preparação acadêmica, o que ratifica a contribuição positi- va do investimento em níveis educacionais para as mulheres (FEM, 2005; BRUSCHINI, 2007) possibilitando a entrada em ambientes mais valorizados e tipicamente ocupados por homens. A maioria deles (4) aponta que essa preparação é a mesma para homens e mulheres, pois se trata de uma exigência legal para $\circ$ cargo. A diferença apontada, segundo eles, está relacionada à eficiência no trabalho e ao perfil de cada delegado.

Todos têm a mesma qualificação. Tá em igualdade por causa do concurso público. Tem uns delegados que são mais eficientes, gostam mais, fazem com dedicação. Têm outros que só fazem o feijão com arroz. Aí, depende muito da personalidade de cada pessoa (E3).

Quando se trata de investimento em formação acadêmica continuada, alguns (2) delegados acreditam que as delegadas estão se qualificando mais que os homens. A vontade e a dedicação para estudar foi apontada como uma característica da "natureza feminina (E2)". Entretanto, o fato de as mulheres investirem mais em educação que os homens, conforme comprovado pelos dados do IBGE (20|4), não pode ser atribuído "á natureza" da mulher, pois se deve considerar a exigência imposta pelo mercado de trabalho e, também, os preconceitos de gênero que pressionam as mulheres a investirem em qualificação, principalmente no saber diferenciado para conquistarem espaço profissional e como estratégia do processo de empoderamento. Conforme os dados demográficos, em relação à formação continuada as delegadas do município estão à frente dos delegados com cursos de pós-graduação (2 delegadas) e mestrado (I delegada), enquanto 
todos delegados possuem somente a graduação.

Quando se trata de conhecimento técnico, relacionado por eles, ao investimento em cursos de tiros e o conhecimento prático, á vivência na atuação operacional, os entrevistados acreditam que os homens investem mais.

Botar uma arma na cintura, um colete à prova de bala e invadir uma casa seis horas da manhã e cumprir uma mandato de busca muitas fazem, mas o percentual das que não fazem é muito maior (E4).

Vários amigos, colegas homens meus já fizeram cursos de tiros, já fizeram cursos de administração de crise, de manuseio de arma. Agora, em meu conhecimento, nenhuma mulher até então chegou e comentou comigo: "Olha eu fiz esse curso também" (E5). Nesse caso, salienta-se o peso da simbologia do estereótipo do delegado, pois ainda espera-se que seja aquele que vai para a rua enfrentar situações perigosas como apontado nos estudos de Hagen (2006) e Bezerra e Lopes (2008), mesmo que atualmente não seja uma exigência funcional para o delegado(a), já que existem policiais responsáveis por essas atividades. Pôde-se perceber que os delegados esperam um desenvolvimento da delegada em relação ao conhecimento técnico e prático comparando à sua própria atuação.

Ressalta-se a importância da aprovação das mulheres no concurso público para delegado(a), pois os delegados equiparam sua qualificação profissional, pelo menos inicialmente, favorecendo o reconhecimento pro- fissional e respeito pelas delegadas, e contribuindo para o processo de empoderamento da mulher.

\section{Fator subjetivo}

De acordo com Melo (20 I2) o fator subjetivo relaciona-se ao desenvolvimento do sentimento "eu posso" fazendo com que as mulheres em seu ambiente profissional se sintam capacitadas para a realização das tarefas. Está associado ao empoderamento psicológico, ao desenvolvimento de sentimentos como autoconfiança, segurança, autoestima elevada que refletem no posicionamento do indivíduo (KLEBA; WENDAUSEN, 2009; MELO, 20I2) e na maneira como as outras pessoas o percebem. Para os entrevistados, as delegadas são igualmente capazes em relação aos delegados. $A$ diferença apontada por alguns (3) relaciona-se a necessidade delas em potencializar os sentimentos de segurança e confiança no ambiente profissional, indicando mais uma vez o modelo mental que possuem da função e sua associação á características consideradas tradicionalmente masculinas.

Quando precisa ter um enfrentamento maior, o número de mulheres que, por exemplo, representa por uma busca apreensão, por uma prisão, botar o colete, ir cumprir, eu acho que as mulheres têm mais receio nisso, mas existem várias que fazem. Não é que seja trabalho pra homem, mas eu acho que nessa parte a mulher acaba ficando mais receosa (E4).

Eu trabalhei com a $\mathrm{Dr}^{\mathrm{a}} \mathrm{XX}$, às vezes você pega, a gente que é homem quer resolver as coisas mais objetivamente. A mulher ela é mais cautelosa, as vezes a mulher tem um pouco de in- 
segurança de fazer determinada análise, ir para determinado local (E3).

Hagen (2006) aponta que nas instituições policiais existe um grupo que é constituído por policiais que estão mais envolvidos com o serviço burocrático da delegacia, e outro, por policiais que gostam de atuar nas ruas. Pôde-se observar essa divisão na percepção dos delegados.

De outra maneira, solicitou-se aos delegados que apontassem competências que consideram essenciais para o trabalho como delegado(a). Eles citaram: ser persistente; buscar motivar a equipe de trabalho; saber ouvir; gostar do que faz; ser disciplinado; buscar prestar o melhor serviço possivel apesar das carências de falta de pessoal e estrutura da instituição; ser disciplinado; ter força de vontade; ser responsável; ter disposição para trabalhar; não praticar nenhum ato imoral. Posteriormente, os delegados apontaram características que se destacavam na atuação das delegadas: ouvem melhor as pessoas que procuram a delegacia; possuem um diferencial positivo no trato com a equipe; são persistentes; são mais sensíveis aos problemas alheios, são mais caprichosas; são mais detalhistas; são mais dedicadas; são mais pacientes.

A mulher, eu acho que ela tem uma visão diferente da de nós homens, no sentido de que às vezes o trato com a equipe, o jeito de lidar, acho que pode influenciar e pode ajudar (E2).

A mulher é mais caprichosa, ela é mais sensível. (...) pra você ter uma idéia, eu tava conversando com a Dra $X X$, ela pegou uma situação em que o preso tava recolhido na prisão injustamente e ela ficou de nove da manhã as nove da noite atrás de um juiz de plantão para entrar com o pedido de liberdade provisória para por o cara em liberdade. Coisa que talvez o homem chutaria o balde (E5).

A maior parte deles (4) atribui às delegadas algumas dessas competências, que consideram essenciais para a função, o que indica que eles identificam a competência profissional e capacidade da mulher para o exercício da profissão policial, o que é favorecida, segundo eles, por algumas características femininas. A avaliação dos delegados revela sentimentos que eles identificam em suas colegas como a empatia, a determinação e a dedicação, o que se mostra favorável para o processo de empoderamento das delegadas. As características destacadas reproduzem aquelas tradicionais das mulheres (BOURDIEU, 20I0), mas nesse caso não aparecem como fator de subjugação, apontando que o que diminui ou enaltece individuos na sociedade são as construções sociais elaboradas acerca das características, que nesse caso é positiva.

\section{Fator político}

O fator político analisa a participação no ambiente político organizacional, seu engajamento, seus relacionamentos e suas estratégias para conquistarem espaços de poder e na alta hierarquia organizacional, buscando identificar a existência de barreiras que dificultam ou impedem a ascensão das mulheres (MELO, 20I2). Para os delegados não existem diferença nas atividades exercidas por homens e mulheres na instituição policial:

Não, não vejo. Tanto que aqui em Ribeirão das Neves a mesma função que eu faço é feito por duas delegadas, com as mesmas...lidando com os mesmos tipos de crimes que eu. Então, não vejo (EI). 
Nenhuma.A mesma carga de responsabilidade que eu tenho. As meninas têm também. Não tem diferença nenhuma, não (E5).

Os delegados também afirmam não existir diferença entre autonomia profissional do delegado e da delegada, pois a autonomia está relacionada, segundo eles, ao perfil do profissional, sendo limitada pela especificidade da função pública. Foi exemplificado que alguns delegados(as) conseguem manter suas decisões em meio às complexidades e desafios do ambiente policial, enquanto outros não, o que na prática, reporta à diferença na autonomia entre esses profissionais.

Eu creio que a mesma. Igual aqui no plantão. A Dra Z, por exemplo, ela é uma pessoa que tem o perfil mais rígido. Então, toma a mesma decisão e tem delegados que são mais, né, deixa...mais relaxado e tudo. Então, vai muito do perfil de cada um (E3).

Os delegados negaram existir diferenças entre gêneros nas disputas entre profissionais com as mesmas qualificações. $O$ conhecimento político surge como fator que influencia nessas disputas e, nesse caso, sendo os homens os que ocupam as mais altas posições, pode haver preferência por outros homens, como uma estratégia de preservação da hegemonia dos homens, o que pode dificultar a ascensão das mulheres.

Não.Aqui não. Por exemplo, cursos de aperfeiçoamento, né, todo mundo tem a mesma qualificação, todo mundo tem as mesmas oportunidades. Depende da pessoa, se ela vai querer (E3).

Não. Acho que a polícia é muito política, né. É vinculada ao Executivo. Aí existe conhecimento político, infeliz- mente (E4).

Segundo a maioria deles (4), a mulher não precisa enfrentar desafios ou dificuldades maiores para ter as mesmas oportunidades que os homens, o que decide $\circ$ crescimento na instituição é a competência e o ajustamento do perfil do profissional a cada delegacia. Todavia, também se identificou que mulheres e homens são designados à delegacias que não se ajustam ao seu perfil, o que sugere que outros critérios são utilizados para essa escolha, podendo ser influenciados pelo peso das simbologias das delegacias, como foi apontado por Bezerra e Lopes (2008) e Silveira (20II) em suas pesquisas.

Não. Eu acho que na Polícia Civil, ela tem que encontrar qual é o perfil dela, né, porque eu já percebi perfis eminentemente operacionais e já nessa linha no oposto, perfis eminentemente burocráticos (E5) Igual, por exemplo, você tem que pegar a mulher que tá mais apta (....) nem toda mulher tem o perfil de ficar...Adolescente, por exemplo, não é toda pessoa que tem. Às vezes, o homem tem o perfil de ta lá numa delegacia e tem outros que não aguentam nem falar em adolescente (E3).

Observou-se a total negação pelos delegados da existência das barreiras de gênero nas relações de trabalho vivenciadas na instituição policial. Considerando essas condições, o processo de empoderamento das mulheres dentro da Policia Civil seria totalmente favorecido, mas, esse posicionamento extremo não traduz a realidade das relações de gênero na sociedade. $O$ que faz refletir que a negação pode ser uma atitude de autodefesa.

Os homens também sofrem com as ex- 
pectativas acerca do seu comportamento no ambiente doméstico, social e de trabalho, sendo muitas vezes considerado culpado pela subjugação das mulheres (LOPES, 2008; PINTO; NUNES; FAZENDA, 20I4). Assim, admitir a existência de preconceitos de gênero nesse ambiente pode parecer uma confissão de que eles reproduzem esses preconceitos. A possível presença da autodefesa indica a necessidade de desconstruir a crença de que a responsabilidade pelas desigualdades de gênero decorre do poder pessoal do homem exercido sobre a mulher, deve-se considerar a influência da raça, da classe e da religião associada às construções culturais de gênero (HOLTER; 2003) e também a objetivação dessas desigualdades por meio das instituições como família, Igreja, Escola e Estado (BOURDIEU, 20I0).

\section{Fator econômico}

A independência financeira é vista pelos delegados como uma conquista das mulheres, responsável por desenvolver a autoestima, a autoconfiança, além de trazer autonomia e liberdade para fazer suas próprias escolhas. Essa percepção confirma que os benefícios do empoderamento econômico ultrapassam as conquistas materiais (FRIEDMANN, 1996; COSTA, 2004; LISBOA, 2008; MELO, 2012 ; PANDEY, 20I3; KABEER, 20I3; PNUD, 20I4), pois afeta o empoderamento psicológico, além de reduzir os preconceitos de gênero (THEWORK BANK, 20I4), o que favorece o desenvolvimento do seu processo de empoderamento.

Eu acho que, geralmente, mulher quando precisa pedir alguma coisa para o marido, o dinheiro, fica meio submissa a ele (EI).
Ah! Eu acho que não. Ah! É bom pra autoestima dela (E2).

Quando ela própria tem o seu próprio dinheiro para fazer as coisas eu acho que ela fica muito mais confiante, muito mais independente na vida dela (E3).

$A$ independência financeira pode ser um problema para algumas mulheres no ambiente doméstico onde podem se deparar com preconceitos da sociedade machista que não aprova o fato de a mulher ganhar mais que o homem.

Olha, nós vivemos em uma sociedade muito machista, eu acho que poucos homens aceitariam a ideia de ter o contracheque mais magro do que o da esposa e isso às vezes pode intimidar (E5).

Entretanto, a mulher precisa romper com essas crenças e ideologias machistas para desenvolver seu processo de empoderamento (COSTA, 2008). Os delegados relataram que os problemas no relacionamento entre homens e mulheres decorrentes do fato de a mulher ganhar mais também pode ser atribuído à mulher, pois ao melhorar sua situação econômica ela pode cobrar que o homem ganhe mais que ela. Nesse caso as mulheres reafirmam as práticas e os papéis tradicionais de homens e mulheres, possibilidade apontada por Bourdieu (2010).

Eu até tenho um amigo que a mulher ganha mais do que ele.Ela cobra ele um pouco. Eu acho, às vezes que até a própria mulher, querendo cobrar, se ganha mais, querendo cobrar do homem pra que o ganhe igual, trabalhe mais, ou ganhar junto com ela. Eu tenho um amigo, inclusive, que a mulher cobra muito dele (EI). 
empoderamento econômico das delegadas é percebido pelos delegados e pode se mostrar positivo ou negativo quando se trata dos reflexos no ambiente doméstico, envolvendo questões diferentes.

\section{Fator social}

Todos os delegados destacaram o crescimento delas na hierarquia institucional com destaque à ocupação dos cargos de chefia, verificando-se uma quebra de paradigmas com a presença da delegada em cargos mais valorizados e predominantemente ocupados por homens nessas instituições.

Eu acho que só de dar um voto de confiança a uma mulher, de chefiar a delegacia regional de Ribeirão das Neves, que, convenhamos, a delegacia regional de Ribeirão das Neves ela é problemática, nós estamos numa região que, no meio policial, normalmente, a gente brinca que aqui é a Faixa de Gaza.Não é brincadeira, não (E5).

O reconhecimento do trabalho das delegadas está associado á apresentação de um resultado positivo por elas em meio às dificuldades e carências do município. $\mathrm{E}$ nesse sentido, Kleba e Wendausen (2009) ressaltam que o empoderamento é vivenciado quando o individuo cria possibilidades e desenvolve competências para lidar com situações adversas.

O reconhecimento pessoal dos delegados as suas colegas de profissão se dá pela valorização da atuação profissional das delegadas em Ribeirão das Neves, apoiado nas justificativas de que: as mulheres estão se destacando na instituição (2); são mais dedicadas (I); são mais detalhistas (I) e fazem um ótimo trabalho na delegacia das mulheres (2):

$\mathrm{Na}$ área da delegacia de mulheres, trabalho excelente que a $D r^{a} Y Y$ que hoje tá aqui no plantão. Quanto a Dra $X X$ fez, trabalho que são áreas especificas da mulher, trabalho excelente. É, a Dr ${ }^{a}$ NN lá no $I^{\circ}$ distrito, é uma área muito violenta, pega as maiores favelas de Ribeirão das Neves, ela também tá conseguindo conduzir de forma muito satisfatória (E3).

Na perspectiva de Deere e León (2002) e Pandey (20l3), com o desenvolvimento do empoderamento, a mulher deixa de ser a parte submissa às decisões alheias, e passa a ter seu posicionamento considerado no seu meio social. Isso pode ser identificado por meio do reconhecimento do trabalho delas pelos delegados.

A maior parte deles (3) afirmou que o trabalho da delegada também é reconhecido pela sociedade, principalmente no atendimento ás vítimas na Delegacia de Mulheres e não percebem preconceito ou resistência nesse sentido.

Acho que a sociedade vê com muita empatia. E, principalmente, quando trabalha nessas áreas especificas de atendimento à mulher, de atendimento à criança e adolescente, ao idoso.A minha sogra, ela era titular da Delegacia de Deficiente e Idoso, então a sociedade vê isso com empatia."Nossa! Que bacana delegada comandando aquele bando de marmanjo!" (E5)

Apesar da importância do trabalho da mulher na delegacia de mulheres, crianças, adolescentes e idosos, somente esse destaque pode impor barreiras para atuação delas nas delegacias mais operacionais que requerem comportamentos e habilidades mais racionais e não emocionais, como as destacadas pelos delegados (HAGEN, 2006; BEZERRA; LOPES, 2008; LOPES; MOTA 
BRASIL, 2010). Observa-se a reprodução da divisão sexual do trabalho e a percepção da separação de setores específicos para gêneros na Polícia Civil, como identificado nos estudos de Bezerra e Lopes (2008) e Silveira $(20 \mathrm{II})$ que destacam que as delegacias associadas a serviços de natureza assistenciais tornam-se as "cadeiras cativas das delegadas", e estando de acordo com - espaço e as características tradicionais reservadas às mulheres. Dois delegados citaram que percebem a existência de certo preconceito e resistência por parte da sociedade em relação à atuação da delegada, ratificando a influência do estereótipo da função apresentado por Sadek (2009).

A questão dos próprios criminosos de ver a mulher e pensar que ela não pode, que ela não tem a capacidade e aí eles...as vezes..(E3).

Acho que a pessoa pode ter uma desconfiança inicial: Ah....coisa da sociedade machista. Mulher!! Se ela chegar e desempenhar o trabalho dela normal, aos poucos, o próprio trabalho demonstra que a pessoa é (E4).

O fator social na percepção dos homens expressa o desenvolvimento do processo de empoderamento das delegadas, pois mesmo considerando a presença de valores da cultura de dominação masculina, eles reconhecem e destacam o trabalho delas no ambiente majoritariamente ocupado por homens e fundamentado em características masculinas, o que não descarta a necessidade de ainda ser necessário romper com os estereótipos.

\section{Fator cultural}

Quanto às dificuldades impostas pela cultura os delegados descreveram que o espaço para as mulheres ainda é pequeno; existe preconceito que impede as mulheres de alcançarem cargos de chefia; a sociedade brasileira é machista e a maternidade é um dificultador para a carreira das mulheres:

Acho que na cultura brasileira ainda está arraigado o machismo.(...)E hoje a mulher tá tomando conta, não só da polícia, né. Ela tem mesmo que tirar mesmo a venda do olho e encarar, porque a sociedade é machista (E3).

Um delegado aponta que, apesar dos preconceitos culturais, a luta pela isonomia entre gêneros contribuiu para a conquista de espaço pela mulher na sociedade, destacando-se a importância dos movimentos feministas das décadas de 1960 e 1970 que incitou o início da construção de uma nova dinâmica dessas relações (SCOTT, I99I; LOURO, 20I I).

Eu acho que essa ideia da isonomia de sexo já amadureceu bastante dentro do consciente coletivo, e isso é um movimento que veio pra ficar, não só por uma questão cultural, mas também por uma questão do aumento do custo de vida (E5).

Quando se trata da cultura da Polícia Civil do município em que atuam, a maior parte dos entrevistados (4) diz não existem barreiras/preconceitos. Os delegados só apontaram barreiras contra a mulher quando não se trata do seu ambiente, o que parece ser novamente um posicionamento de autodefesa.

Não. Dentro da instituição entre nós, não, mas há comentários. Por exemplo, aquele advogado, que foi pego usando drogas...ele fez um comentário debochado da $X X X$. Na época, eu não tava mais na Homicídio, da YYY também, duas delegadas que na época 
estavam conduzindo o caso. Ele chamou uma de paquita e outra de Mega Hair, comentário direcionado por elas serem mulheres (E4).

Apenas um delegado afirmou que as mulheres sofrem preconceito por se mostrarem inseguras, receosas no desenvolvimento de sua função, e também pela pouca atuação operacional, ou seja, não reproduz as características masculinas tradicionais, ainda esperadas para o cargo, assim como alguns homens também não possuem, mas são menos visados, se destacando o preconceito.

Às vezes se tem por causa dessa questão de insegurança. Às vezes, a delegada que tá novata vai passar pelo estágio probatório de dois anos, ela fica com receio de cair no abuso, $\mathrm{e}$ isso, às vezes, pode gerar o que falar. Eles falam: "Ela tá com medo, ela não tem o perfil para a atividade". Mas isso aí até o homem também.. Porque os investigadores, eles querem um delegado que tá no combate de frente com eles, que tão pulando muro, que tão trocando tiro, aquele trem todo. $E$, às vezes, pelo fato de ser mulher, eles podem ligar isso ao gênero, pelo próprio machismo (E3).

Em relação a reprodução ou ao rompimento dos valores culturais tradicionais a maior responsabilidade da mulher na esfera doméstica foi citada como uma prática ainda vigente que pode favorecer o homem no ambiente profissional em detrimento da mulher, indicando como afirma Melo (2012) a influencia das outras esferas da vida da mulher em seu processo de empoderamento.

A responsabilidade das mulheres quanto as questões familiares pode ser usada para afastá-las de ambientes profissionais mais exigentes, com a alegação de que elas não teriam disponibilidade para desenvolver essas atividades profissionais em razão de seus compromissos na esfera doméstica. Essa crença é baseada na expectativa da sociedade quanto ao papel de mãe e da esposa. Infere-se aqui que a questão não está relacionada à disponibilidade e ao compromisso profissional da mulher. Entretanto, o acúmulo da dupla, ou tripla jornada reflete em maior desgaste para a mulher, não só em seu ambiente profissional, o que pode favorecer a atuação do homem. Dessa forma, existem barreiras culturais fortemente internalizadas ou externalizadas.

\section{Considerações Finais}

O objetivo desta pesquisa foi analisar a percepção dos delegados da Polícia Civil de Ribeirão das Neves acerca do empoderamento profissional das delegadas do mesmo município. Considerando a percepção dos delegados, o processo de empoderamento das delegadas está ocorrendo, entretanto, esse processo não demonstrou ser tarefa fácil, pois as mulheres estão sob julgamentos e comparações constantes dos homens e eles procuram padronizar as ações dos profissionais, considerando os comportamentos e práticas tradicionais masculinas, como a cobrança pela atuação externa das delegadas, que não é uma exigência funcional.

O destaque para a atuação das mulheres nas delegacias de mulheres não significa um problema para o processo de empoderamento. $O$ problema está em como os homens, mesmo de forma inconsciente, parecem querer manter a delegada em um lugar que não representa competitividade para eles, ratificando a divisão sexual do 
trabalho e os espaços que consideram femininos e masculinos.

A presença cada vez maior da mulher policial contribui para o enfraquecimento da cultura patriarcal institucional e social, favorecendo o processo de empoderamento da mulher. Salienta-se que a representatividade das mulheres no município trouxe mudanças positivas para as relações de gênero na instituição, que podem ser percebidas por meio do reconhecimento e da contribuição do trabalho das mulheres para o município e para a instituição, colaborando para novas construções sociais e culturais acerca das relações de gênero e de poder. Há de se destacar o próprio posicionamento dos delegados que tentam rejeitar a reprodução dos preconceitos, embora algumas vezes eles sejam reproduzidos inconscientemente por eles, indicando a força dos princípios da dominação masculina na sociedade, pois se encontram internalizados.

Acredita-se que a relevância deste estudo está principalmente em discutir a perspectiva do homem em relação ao fe- nômeno do empoderamento da mulher. $\mathrm{O}$ empoderamento trata-se de um processo relacional que está sendo construído por meio das complexas relações sociais e sexuais desenvolvidas entre homens e mulheres cotidianamente, o que pede, portanto, a análise de como o homem tem afetado e percebido esse processo. Os primeiros estudos sobre gênero desenvolvidos pelas militantes feministas tinham o objetivo de inserir a mulher na história, já que havia sido por muito tempo ignorada (LOURO, 20II; SOIHET; SOARES; COSTA, 20I2), mas é necessário, não ignorar o papel do homem na perspectiva de gênero.

Sugere-se ampliar as pesquisas acerca do empoderamento da mulher e de seu impacto nas relações sociais e domésticas e confrontar as perspectivas do homem e da mulher sobre o empoderamento.Considera-se como limitação da pesquisa o fato da coleta dos dados ter sido realizada em somente um município, o que pode não representar a realidade de distritos policiais de outros lugares. 
BARDIN, L. Análise de conteúdo. São Paulo, Edições 70, 1994.

BEZERRA,T. C. E.; LOPES, E. B. Quem são as mulheres da Polícia Civil? In: BRASIL, G. M. (org.) A face feminina da polícia Civil: gênero, hierarquia e poder. Fortaleza: EdUACE, 2008, p. 16-70.

BOURDIEU, P. A dominação Masculina. Tradução Maria Helena kuhner. 9. ed. Rio de Janeiro: Bertrand Brasil, 2010. 160 p.

BRUSCHINI, C. Trabalho e gênero no Brasil nos últimos 10 anos. In: Seminário Internacional Mercado de Trabalho e Gênero: comparações Brasil-França, 2007, Rio de Janeiro. Anais... Rio de Janeiro: UFRJ/ IFCS, 2007.

COSTA, A.A.Gênero, poder e empoderamento das mulheres. Salvador. 2004. Disponível em: <http://www.agende.org.br/docs/ File/dados

_pesquisas/feminismo/Empoderamento\%20-\%20Ana\%20Alice. pdf>. Acesso em: 12 set. 2014.

DEERE, C. D.; LEÓN, M. O empoderamento da mulher:direitos à terra e direitos de propriedade na América Latina. Tradução de Letícia Vasconcellos Abreu, Paula Azambuja Rossato Antinolfi, Sônia Terezinha Gehering. Porto Alegre: Editora da UFRGS, 2002.

ERNST;YOUNG - EY.World Wide Women Public Sector Leaders Index 20l4: opening the door for women working in government. Disponível em: <http://www.ey.com/Publication/vwLUAssets/EY_-_Worldwide_Women_Public_Sector_Leaders_Index_20I4/\$FILE/ EY_Worldwide_Index_of_Women_22Octl4.pdf>. Acesso em: 10 jan.20I5.

FÓRUM ECONÔMICO MUNDIAL
- FEM. Empoderamento de mulheres: avaliação das disparidades globais de gênero. Genebra, 2005.

FRIEDMAN, J. Empowerment: uma política de desenvolvimento alternativo. Oeiras: Celta, 1996.

GODOY, A. S. Estudo de caso qualitativo. In: GODOY, Christiane Kleinübing et. al (Org). Pesquisa Qualitativa em estudos organizacionais: paradigmas, estratégias e métodos. São Paulo: Saraiva, 2006. Cap. 4, p. I I 5- I 46.

HAGEN,A. M. M..Relações de gênero no trabalho policial. In: $30^{\circ}$ Encontro Anual da Associação Nacional de Pós-Graduação e Pesquisa em Ciências Sociais, 30, 2006, Rio Grande Sul. Anais... Rio Grande do Sul:ANPOCS, 2006, p. I - I 5.

HARTLEY, J. F. Case studies in organizational research. In: CASSEL, C; SYMON, G. (Ed.). Qualitative methods in organizational research: a practical guide. London: Sage, 1999, p. 208-209.

HIRATA, H.; KERGOAT, D.. Novas configurações da divisão sexual do trabalho.Cadernos de Pesquisa, v. 37 , n. 132, p. 595-609, 2007.

HOlTeR, O. G. Can Men do It? Men and Gender Equality:The Nordic Experience. Copenhagen, Denmark: Nordic Council of Ministers, 2003.

INSTITUTO BRASILEIRO DE GEOGRAFIA E ESTATÍSTICA - IBGE. Pesquisa Nacional por Amostra de Domicílios - PNAD: Brasil e Síntese de Indicadores 2013. Disponível em: <http:// www.ibge.gov.br/home/presidencia/noticias/imprensa/ppts/

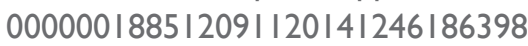
59.pdf>.Acesso em: I5 jan.20I5. KABEER, N. Contextualizando as trilhas econômicas do empoderamento de mulheres: resultados de um programa de pesquisa em diferentes países. Revista feminismos, v. I, n. 2, p. I-28, ago.20I 3.

LAGARDE, M. Género y feminismo: desarrollo humano y democracia. Madrid: Horas \& horas, 1996.

LISBOA, T. K. Mulheres migrantes de origem cabocla e seu processo de empoderamento. Gênero, Núcleo Transdisciplinar de Estudos de Gênero, Niterói, v. 2, n. 2, p.|3|-|49, 2002.

LISBOA, T. K. O empoderamento como estratégia de inclusão das mulheres nas políticas sociais. Fazendo gênero, Santa Catarina,n.8, p. I-6, ago. 2008.

LOCATELLI, P.A. P. C.; BRUNETA, N.; OLIVEIRA, L. Y. N.; PICCININI, V.M.. Mulheres na Polícia Civil: um olhar sobre as relações de gênero e identidade. Gestão Contemporânea, n. 14, p. 9-34, jul./dez. 2013

LOPES, E. B.; BRASIL, G. M. Mulheres na polícia: demarcação dos espaços de comando e relações assimétricas de poder. Fazendo Gênero-Diásporas, Diversidades, Deslocamentos, v. 9, p. I-9, 2010.

LOURO, L. C. Gênero, sexualidade e educação: uma perspectiva pós-estruturalista. 12.ed. Petrópolis:Vozes, 20I I. 184p.

MAHADEVI.M. T. Women's empowerment and Panchayat Raj. Golden Research Thoughts, v.3, n.3, p. 3-5, set.20I3.

MELO, M. C. O. L. Mulheres gerentes entre o empoderamento e o teto de vidro. In: FREITAS, M. E.; DANTAS, M. (Orgs.). Diversidade Sexual e Trabalho. I. ed. São Paulo: CNL - CENGAGE/NACIONAL, 
20I2. 384p.

MELO, M. C. O. L.; LOPES,A. L. M. Empowerment de Mulheres Gerentes: Construção de um Modelo Teórico para Análise. In: Encontro da Associação Nacional de PósGraduação e Pesquisa em Administração, 35, 20 I I, Rio de Janeiro. Anais... Rio de Janeiro: ANPAD, 20II, p.I-I7.

MINAS GERAIS. Polícia Civil. Disponivel em <https://www.políciaCivil.mg.gov.br>. Acesso em: 18 nov. 2014.

PANDEY, J. Ki. Women empowerment through self help group: a theoretical perspective. Golden Research Thoughts, v. 2, n. 8 , p.3-7, feb. 2013

PINTO, N.; NUNES, S. M.; FAZENDA, R. Um estudo sobre a influência do género em funções tradicionalmente masculinas e femininas. International Journal on Working Conditions, p. 17-33, n.7, jun. 2014.

PORTER, E. Rethinking women's empowerment.Journal of peace building \& development, p. I-I5, v. 8 n. I, jul.20I3.

PROGRAMA DAS NAÇÕES UNIDAS PARA O DESENVOLVIMENTO - PNUD. Relatório do Desenvolvimento Humano de 20 14. Disponível em <http:// www.pnud.org.br/arquivos/ RDH20I4pt.pdf>. Acesso em: 26 dez. 2014.

RATHO, S. P. Empowerment of women through human. Rights education: an analysis. Golden Research Thoughts, v. 2, n. 8, p.3-II, feb. 2013.

SADEK, M. T. Delegada: Doutora e Policial. In: SADEK, Maria Tereza (Org.). Delegados de Polícia. Rio de Janeiro: Centro Edelstein de Pesquisas Sociais, 2009. 89p.

SCOTT, J. Gênero: categoria útil de análise histórica. Educação e realidade, Porto alegre, v. 20, n. 2 , p. 71-99. 1991.

SECRETARIA DO ESTADO DE DEFESA SOACIAL - SEDS. Unidades prisionais - Ribeirão das Neves. Disponível em: <ht- tps://www.seds.mg.gov.br/index. php?option=com_content\&task $=$ view\&id $=288 \&$ Itemid $=>A$ cesso em: 26.jan.20I5.

SOARES, B. M.; MUSUMECI, L. MuIheres policiais: presença feminina na Polícia Militar do Rio de Janeiro. Rio de Janeiro: Civilização Brasileira, 2005.

SPREITZER, G. Taking Stock: A Review of More Than Twenty Years of Research on Empowerment at Work. In: BARLING, J.; COOPER, C., The SAGE Handbook of Organizational Behavior, v.I, p. 54- 72. Londres: SAGE Publications, 2008.

STROMQUIST, N. La busqueda Del empoderamiento: em qué puede contribuir El campo de La educación. In: LÉON, M. (Org.). Poder y empoderamiento de lãs mujeres. Bogotá: MT Editores, 1997. THE WORK BANK.Women; Business and the Law 2014: removing restrictions to enhance gender equality. London: Bloomsbury Publishing, 2014. 